The first meeting of the MEOC, since its incorporation in November 1980, has produced a number of very important results. Primarily, it has enabled the outreach coordinators at the 11 federally funded centers, as well as members of other universities, business groups, community organizations, and members of the national media, to pool their efforts toward promoting better understanding of the cultures and peoples of the Middle East countries, including the Arab world, Iran and Israel. Foremost among the MEOC's priorities is the need to coordinate efforts in the direction of promoting public awareness of the Middle East without, in any way, becoming politicized or falling victim to the dictates of any special interest group or organization. As a non-profit, tax-exempt organization, MEOC's charter designates its activities to "coordinate and promote the dissemination of information and materials on the Middle East for educational purposes." The organization cannot lobby or become a political action group.

Rather, the MEOC seeks to work through schools, constituents in the business and news communities, as well as with the general public, to produce a better understanding in this country of the history, culture and institutions of the Middle East. The Department of Education's mandate for "outreach" - dissemination of information on the Middle East at the local and national levels - through its Title VI Foreign Language and Area Studies awards, has been actively participated in by funded Middle East Centers at universities throughout the U.S. for a number of years. By incorporating, the current $11 \mathrm{M}$.E. Center outreach coordinators can formally link with others involved in similar activities at other schools and universities, and draw in the various, interested business corporations and members of the news media who deal with the Middle East. It is felt that the MEOC will provide the umbrella organization to give this constituency a sense of identity and also a continuity which will make our efforts stronger.

At the conclusion of the Wingspread Conference there was a general feeling that the important ideas and comments made at each of the sessions should be made available to other interested individuals who were not able to attend. Therefore, a booklet containing this information is being prepared for publication, and will be available at the next MESA meeting. Or, copies can be obtained by writing: Sheila Scoville, Outreach Coordinator, Near Eastern Center, Franklin BIdg.. University of Arizona, Tucson, AZ 85721.

The MEOC Newsletter, with information on outreach activities and materials available in the field, can be obtained through: Vernon Eggar, Outreach Coordinator, Center for Near Eastern and North Af-

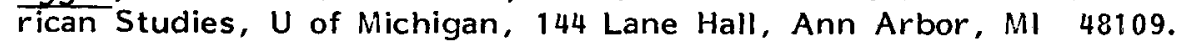

\title{
The Population Council
}

The Population Council, with funding from the U.S. Agency for International Development, has organized an International Research Awards Program on the Determinants of Fertility in Developing Countries. The objective of the program is to support research that will increase understanding of why and how human fertility changes in different cultural settings and under varying socio-economic conditions. The program is organized as a competition based on peer review of research proposals. A Program Committee of distinguished social scientists provides policy guidance for the operation of the program, oversees the peer review process, and makes decisions on awards.

Proposals may be submitted by one or more individuals affiliated with an institution in developing or developed countries. Preference will be given, first to proposals from developing country institutions 
and, second, to proposals representing a collaborative effort between a developing country and another institution.

Inquiries about the program and application procedures are available from: Charles Keely, Program Manager, The Population Council, 1 Dag Hammarskjold Plaza, New York, NY 10017.

\section{Society for Textual Scholarship}

The Society invites applications for membership from scholars interested in an interdisciplinary discussion of textual theory and practice; and concerned with any aspect of the enumeration, description, transcription, editing or annotating of texts in any discipline. The Society convenes for a two-day conference every year, and publishes an annual, hardback volume of transactions called Text, of 350 pages. This is sent free to all members. In addition, members receive periodic Newsletters containing correspondence, reviews and bibliographies of interest to scholars in various disciplines. The inaugural conference was held at City University of New York, April 10-11, 1981. Individual memberships: $\$ 20$; Institutions: $\$ 30$; Students: $\$ 10$. For further information, contact: Text Correspondence Secretary, Room H-428, Queensborough Community College, Springfield BIvd., Bayside, NY 11364.

\section{TEACHING MATERIALS \\ "Decision-Making in a Technological Environment: The Case of the A swan High Dam"}

Robert W. Rycroft and Joseph S. Szyliowicz of the Technology, Modernization and International Studies Program of the Graduate School of International Studies, University of Denver, have prepared a 108page case study to serve as a basis for classroom discussions. This study is distributed by: Intercollegiate Case Clearing House, Soldier's Field, Boston, MA 02163.

\section{The World of Islam, Images and Echoes}

The Islamic Teaching Materials Project is pleased to announce the publication of The World of Islam, Images and Echoes, an annotated catalogue reviewing some 250 English language films on the Islamic world. Sponsored and distributed by the American Council of Learned Societies, and underwritten by ICF, it was produced under the general editorship of Ellen-Fairbanks Bodman. Copies: $\$ 9.50$ prepaid. Contact: "Images" - American Council of Learned Societies, 800 3rd Ave., New York, NY 10022.

\section{The Middle East: The Image and the Reality}

The Middle East: The Image and the Reality by Jonathan Friedlander, ed. Mark Newman. Los Angeles: Regents of University of California, 1980.

"Something for everyone" describes this handbook of discussions on teaching about the Middle East. In his Preface, Friedlander says that the publication attempts to meet "the needs of instructors, planners and pupils as they confront head-on the challenges brought on by decades of neglect and arrogance."

Surprisingly, in most respects, this volume is successful. The background sections on teaching about the Middle East and multicultural education provide a very good rationale for the inclusion of units on the Middle East. Jose da Silva Goncalves does an excellent job of 